\title{
Study on Tea Saponin Extraction from Shell of Oil -tea Camellia Seeds
}

\author{
$\mathrm{Ma} \mathrm{Li}$ \\ ${ }^{1 .}$ Central South University of Forestry \\ and Technology, Changsha 410004, \\ Hunan, China; \\ 2. Hunan Academy of Forestry, \\ Changsha 410004, Hunan, China
}

\author{
Zhong Haiyan \\ Central South University of Forestry \\ and Technology, Changsha 410004, \\ Hunan,China
}

\author{
Chen Yongzhong \\ 1. Central South University of Forestry \\ and Technology, Changsha 410004, \\ Hunan,China; \\ 2. Hunan Academy of Forestry, \\ Changsha 410004, Hunan, China
}

\begin{abstract}
In order to effectively use the waste oil-tea camellia seed shell and reduce environmental pollution, this paper presented a tea saponin extraction method by using tap water as the extraction agent and precipitation method from oil-tea camellia seed shell.The best extraction conditions and parameterize the factors were optimized for tea saponin extraction from oil-tea camellia seeds: the extraction temperature is $80^{\circ} \mathrm{C}$, ratio of liquid to solid is $6: 1, \mathrm{pH}$ value for extraction is 9 and the extraction time is $6 \mathrm{~h}$. The final tea sapnin extraction rate could reach $94.66 \%$. The best precipitate and tea saponin release agent recipe are obtained: Poly aluminum chloride (30\% concentration) is the suitable flocculant and the optimum amount is $8 \%$ of preliminary extracted liquid by weight and placed still for 2 hrs. The optimum amount of $\mathrm{CaO}$, as precipitate agent, is $10 \%$ of the weight of the raw materials, and stirred for $4 \mathrm{~h}$. The release agent, ammonium bicarbonate, was used in an amount of the $30 \%$ of the tea saponin calcium in order to achieve a chemical equilibrium reaction rate of $50 \%$.
\end{abstract}

Keywords-oil -tea camellia seeds; tea saponin; extraction

\section{INTRODUCTION}

Tea saponin, consisting of triterpenoid saponins, structural sugar and acid structure, is traditionally extracted from oil -tea camellia seeds; ${ }^{[1]}$. The pure tea saponin is milky white or pale yellow solid amorphous powder, and its melting point ranges from 223 to $224{ }^{\circ} \mathrm{C}$. The molecular formula is $\mathrm{C}_{57} \mathrm{H}_{90} \mathrm{O}_{26}$ and the relative molecular mass is $1203^{[2-3]}$. The crystallized saponin is soluble in water content of methanol, ethanol, butanol and glacial acetic acid, and it can be dissolved in hot water, hot alcohol, but insoluble in cold water, ethanol, can not be dissolved in ether, chloroform, petroleum ether and benzene ${ }^{[4,5]}$. Tea Saponin is not only an excellent natural non-ionic surface active agent, which can be used for emulsification, dispersion, wetting, detergency, forming, foaming stability and other surfactants ${ }^{[6,7]}$. Tea saponin has biologically active roles, such as hemolysis, fish toxicity, impermeability of anti-inflammatory, cough analgesic, antibacterial, insecticidal and inhibition of alcohol absorption, the class of biological hormones, etc ${ }^{[8,9]}$.

Oil -tea camellia is very rich of resources in China, the cultivation area is over 45 million mu, and annual output of oil -tea camellia seeds is more than 100 million tons ${ }^{[10-11]}$.
Traditionally, the shells of oil -tea camellia seeds were entirely discarded as by-products during the oil -tea camellia oil extraction process from oil -tea camellia seeds[12-13]. There is $5-8 \%$ of tea saponin in oil -tea camellia seed shell, and the tea saponin could be extracted and be widely used in chemical pharmaceutical, building materials, food, textile, printing, pesticides, aquaculture and other industries, thus increase substantially the accessary value of the oil -tea camellia ${ }^{[14-16]}$. However, few studies so far, to our knowledge, have been reported to extract tea saponin from shell of oil -tea camellia seeds. To increase the tea saponin extraction ratio from shell of oil -tea camellia seeds, The tea saponin extraction conditions and parameter of extraction process were optimized from oil -tea camellia seed shell by using the tea saponin extraction technology from oil -tea camellia seeds as reference.

\section{Materials AND MethodS}

\section{A. Main materials and reagents}

The shell of oil -tea camellia seeds was obtained from Hunan Academy of Forestry. The materials for tea saponin are listed as follows: tap water, distilled water, concentrated sulfuric acid, $77 \%$ sulfuric acid, $8 \%$ vanillin and $30 \%$ poly aluminum chloride (analytical grade), calcium oxide (industrial grade) and ammonium bicarbonate (analytical grade)

\section{B. Main instruments}

- The following instruments were used for tea saponin extraction:

- Desktop pipe rack centrifuge TDL-5Z from Hunan Star Scientific Scientific Instruments Co., LTd.

- Electric blast oven from Shanghai Chongming Experimental Instrument Factory

- UV-2550 UV-Vis spectrophotometer from Shimadzu consumables sales company

- JJ-1 precision electric mixer from Changzhou Sino Instrument Co., Ltd.

- Significant number of electric water bath pot from Shanghai Yuejin Medical Instrument 
- Chinese medicine grinder from Tianjin Teste Instrument Co., Ltd.

- Trace continuously adjustable pipette from Beijing Qingyun Zhuoli Precision Equipment Co., Ltd.

- DZF-OB vacuum oven from Shanghai Yuejin Medical Instrument Factory,

- SHB-III recycled water use of the vacuum pump from Zhengzhou Great Wall Division Industry and Trade Co., Ltd.

- Electronic Analytical Balance from Australia House Instruments (Shanghai) Co., Ltd.

\section{Extraction methods}

\section{1) Tea saponin standard curve}

\section{a) Preparation of standard tea saponin solution}

The standard tea saponin solution $(0.9 \mathrm{mg} / \mathrm{ml})$ was prepared with following protocol: $0.1000 \mathrm{~g}$ standard tea saponin powder (containing $90 \%$ tea saponin) was weighted precisely and placed in a $100 \mathrm{ml}$ volumetric flask,then dissolved with appropriate amount of $80 \%$ ethanol, and then more ethanol were added and set the volume to the mark to make it $0.9 \mathrm{mg} / \mathrm{ml}$ and shake evenly.

\section{b) Measurement method}

The precise amount of the standard solution $(0.5 \mathrm{ml})$ were gauged and placed in a $10 \mathrm{ml}$ test tube with stopper, which was put in a ice-water bath, then $0.5 \mathrm{ml} 8 \%$ vanillin solution and $5 \mathrm{ml} 77 \%$ sulfuric acid were added. After fully shaking the test tube, the test tube was transferred to an intermittent warming water bath $\left(60^{\circ} \mathrm{C}\right)$ for coloring for $20 \mathrm{~min}$, then taken to cool down in a ice-water bath for another $10 \mathrm{~min}$. Then the absorbance of the solution was measured with $1 \mathrm{~cm}$ cuvette at the wavelength of maximum absorption $545 \mathrm{~nm}$ (VU-2008 UV-visible spectrophotometer scanning) by using the blank one as reference after the tube was taken off the ice-water bath and resumed to room temperature.

\section{c) Graphing the standard curve and the determination} of formula

A series of the standard solution $(0 \mathrm{ml}, 0.1 \mathrm{ml}, 0.2 \mathrm{ml}, 0.3$ $\mathrm{ml}, 0.4 \mathrm{ml}$ and $0.5 \mathrm{ml}$ ) were taken and the mixed solutions were prepared with method described in 1.3.1.2 and the absorbance values were measured. Hereby, the standard curve was made and the calculation formula was assessed with excel.

2) Tea saponin extraction procedure with water solvent method

Shell of oil -tea camellia seeds $\rightarrow$ grinding and sieving $\rightarrow$ soaking in solvent $\rightarrow$ centrifugal separated liquid $\rightarrow$ flocculation $\rightarrow$ centrifugal

separated liquid $\rightarrow$ precipitation agent added $\rightarrow$ centrifugation for saponin cake $\rightarrow$ saponin $\quad$ release $\rightarrow$ vacuum $\quad$ filtration $\rightarrow$ vacuum condensing $\rightarrow$ tea saponin crystal

The shells of oil -tea camellia seeds were picked by hands and ground with Chinese medicine grinder and sieved with 20 meshes sieve. Sieved oil -tea camellia seed shell powder was sucked and stirred in hot water for a certain time and centrifugated with Desktop pipe rack centrifuge TDL-5Z to get the preliminary extracted liquid. To remove the impurities in the preliminary extracted liquid, a certain amount of flocculants were added to the preliminary extracted liquid and placed at room temperature for about 4 hour, until there are no suspended solids. Here the purified extracted liquid was obtained after centrifugation. A certain amount of precipitation agent $(\mathrm{CaO})$ were added to the purified extracted liquid and stirred sufficiently to get the saponin precipitate after centrifugation. Then ammonium bicarbonate, the tea saponin release agent, was added to the saponin precipitate. When the reaction of tea saponin with calcium was fully conducted, the mixed liquid was filtered with SHB-III recycled water use of the vacuum pump twice, one is the mixed liquid and the other is the vacuum suction filtered liquid residue, which was washed with hot water again. These two sets of filtered liquid were merged as the crude tea saponin extracts. After the vacuum concentration process, here is the crude tea saponin crystal. In the process of the tea saponin extraction, the solvent and extraction process is the key part of the whole experiment, which determines the extraction ratio of the tea saponin from shell of oil -tea camellia seeds, The extraction parameters, including extraction time, temperature, ratio of liquid to solid and $\mathrm{pH}$, were determined with the single factor experimental design.

\section{a) Trail for Ratio of liquid to solid}

8 parts ground and sieved oil -tea camellia seed shell powder, each $50 \mathrm{~g}$, were prepared and mixed with solvent. The ratio of liquid to solid were $2: 1,3: 1,4: 1,5: 1,6: 1,7: 1,8: 1$, $9: 1$, respectively. The $\mathrm{pH}$ is adjust to 7 , and all the tubes were placed at a $80{ }^{\circ} \mathrm{C}$ water bath for 4 Hours. The extracted tea saponin content of each treatment was measured through the process of centrifugation, flocculation, centrifugation etc., according to the extraction protocol as described above.

\section{b) Trail for extraction temperature}

8 parts ground and sieved oil -tea camellia seed powder, each $50 \mathrm{~g}$, were prepared and mixed with solvent at ratio of $8: 1$. After adjusting $\mathrm{pH}$ to 7 , the tubes filled with solvent and shell powder were sucked and extracted for $4 \mathrm{hrs}$ in $40^{\circ} \mathrm{C}$, $55^{\circ} \mathrm{C}, 65^{\circ} \mathrm{C}, 70^{\circ} \mathrm{C}, 75^{\circ} \mathrm{C}, 80^{\circ} \mathrm{C}, 85^{\circ} \mathrm{C}$ and $90^{\circ} \mathrm{C}$ water bath, respectively. Then the extracted tea saponin content of each treatment was measured through the processes of centrifugation, flocculation, centrifugation etc., according to the extraction protocol as described above.

\section{c) Trial for extraction time}

6 parts ground and sieved oil -tea camellia seed shell powder, each $50 \mathrm{~g}$, were prepared and mixed with solvent at ratio of $8: 1$ and put at a $80^{\circ} \mathrm{C}$ water bath. After adjusting $\mathrm{pH}$ to 7 , the tubes filled with solvent and shell powder were sucked and extracted for $1 \mathrm{~h}, 2 \mathrm{~h}, 3 \mathrm{~h}, 4 \mathrm{~h}, 5 \mathrm{~h}$ and $6 \mathrm{~h}$, respectively. Then the extracted tea saponin content of each treatment was measured through the processes of centrifugation, flocculation, centrifugation etc., according to the extraction protocol as described above.

\section{d) Trail for $\mathrm{pH}$ value}

8 parts ground and sieved oil -tea camellia seed shell powder, each $50 \mathrm{~g}$, were weighed and mixed with solvent at 
ratio of $8: 1$ and place them at a $80^{\circ} \mathrm{C}$ water bath for $4 \mathrm{hrs}$ after the $\mathrm{pH}$ values were adjusted to $4,5,6,7,8,9,10$ and 11 , respectively. Then the extracted tea saponin content of each treatment was measured through the processes of centrifugation, flocculation, centrifugation etc., according to the extraction protocol as described above.

\section{e) Orthogonal experiment for extraction}

According to the previous results from the single factor trial for tea saponin extraction, orthogonal experiments, $\mathrm{L}_{9}\left(3^{4}\right)$, were designed with four factors (temperature, ratio of liquid to solid, $\mathrm{pH}$ value and extraction time) and three levels for the tea saponin extraction from shell of oil -tea camellia seeds, as shown in Table 1.

\section{TABLE 1 LIST OF FACTORS AND LEVELS OF ORTHOGONAL TEST} L9(34)

\begin{tabular}{ccccc|}
\hline levels & A & B & C & D \\
1 & 70 & $5: 1$ & 9 & 4 \\
2 & 80 & $6: 1$ & 10 & 5 \\
3 & 90 & $7: 1$ & 11 & 6 \\
\hline
\end{tabular}

\section{f) Selection and dosage of flocculant}

6 parts preliminary extracted liquid, each $200 \mathrm{~g}$ were weighed. $5 \%, 8 \%$ and $10 \%$ of the weight of extracted liquid, that is $10 \mathrm{~g}, 16 \mathrm{~g}$ and $20 \mathrm{~g}$ poly aluminum chloride (concentration 30\%) were added to the former three parts of preliminary extracted liquid, respectively, and 1\%, 2\% and $3 \%$ of the weight of extracted liquid, that is $2 \mathrm{~g}, 4 \mathrm{~g}$ and $6 \mathrm{~g}$ alum were added to the latter three parts of preliminary extracted liquid. The tea saponin yields were measured after placed at room temperature for $2 \mathrm{hrs}$ and centrifugation separation.

g) Determination of the $\mathrm{CaO}$ amount as precipitate agent

7 parts preliminary extracted liquid after extracting from $50 \mathrm{~g}$ ground and sieved oil -tea camellia seed shell each, were prepared. Then $6 \%, 7 \%, 8 \%, 9 \%, 10 \%, 11 \%$ and $12 \%$ of the weight of oil -tea camellia seed shell, that is $3 \mathrm{~g}, 3.5 \mathrm{~g}, 4 \mathrm{~g}, 4.5 \mathrm{~g}$, $5 \mathrm{~g}, 5.5 \mathrm{~g}$ and $6 \mathrm{~g} \mathrm{CaO}$ powder were added, respectively. After placed for $4 \mathrm{hrs}$ at room temperature and separated the liquid from saponin calcium through centrifugation, the saponin obtained was measured and the relationship between the added amount of $\mathrm{CaO}$ and tea saponin conversion ratio was assessed.

h) Determination of ammonomium bicarbonate amount as tea saponin release agent

According to the reaction equation

$$
(\mathrm{R}-\mathrm{sap}) 2 \mathrm{Ca}+2 \mathrm{H}-\mathrm{N} \rightarrow 2 \mathrm{R}-\mathrm{sapH}+\mathrm{Ca}(\mathrm{N})_{2} \downarrow
$$

$\mathrm{R}$-sapH represents the tea saponin molecules ( $\mathrm{R}=$ sapogenin, $\mathrm{H}=$ the carboxy hydrogen atom), $\mathrm{HN}$ represents saponin release inhibitor ( $\mathrm{N}$ is -1 price).

6 parts of the same weight of saponin calcium, each $100 \mathrm{~g}$ were prepared. Then $10 \%, 20 \%, 25 \%, 30 \%, 35 \%$ and $40 \%$ of the weight of saponin calcium, that is $10 \mathrm{~g}, 20 \mathrm{~g}, 25 \mathrm{~g}, 30 \mathrm{~g}, 35 \mathrm{~g}$ and $40 \mathrm{~g}$ ammonium bicarbonate were added, respectively. After placed and stirred at a $60^{\circ} \mathrm{C}$ water bath for $2 \mathrm{hrs}$, and the liquid was obtained through vacuum filter. The solid residues were washed a small amount of hot water and vacuum filtered again. These two sets of filtered liquid were mixed and the saponin content was measured to evaluate the impact of saponin release agent amount on the saponin release rate.

\section{RESULTS AND DISCUSSION}

A. Graphing the standard curve and determination of the formula

\section{1) The standard curve}

TABLE 2 THE TEA SAPONIN CONTENT AND ABSORBANCE FOR THE STANDARD CURVE

$\begin{array}{ccccccc}\begin{array}{c}\text { Tea saponin } \\ \text { content (ug) }\end{array} & 0 & 90 & 180 & 270 & 360 & 450 \\ \text { Absorbance(A) } & 0 & 0.123 & 0.181 & 0.268 & 0.319 & 0.412\end{array}$

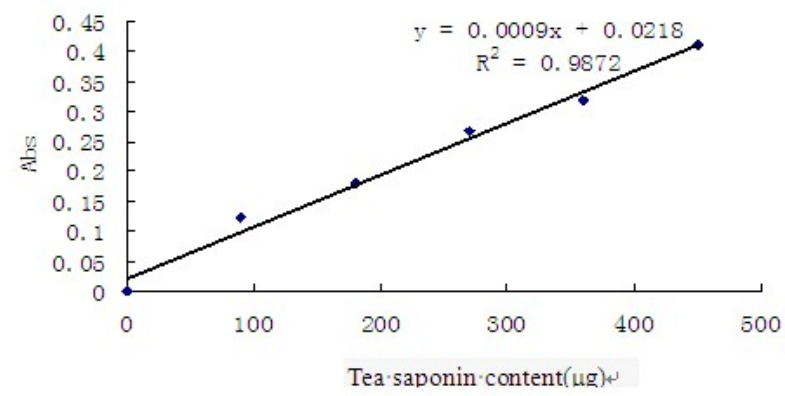

Fig-1 Standard curve of oil tea saponin (Vanillin-oil of vitriol color reaction)

\section{2) Determination of the formula}

According to the absorbance of the standard tea saponin solution and the standard curve with vanillin sulfuric acid colorimetric method, which is obtained at the maximum absorption wavelength of $545 \mathrm{~nm}$ at different concentration of tea saponin, the regression equation is as follow:

$$
\mathrm{A}=0.0009 \mathrm{x}+0.0218 \text {. }
$$

then combined with the standard curve, tea saponin content is calculated with equation:

Tea saponin $\%=(\mathrm{A}-0.0218) / 0.0009 \mathrm{~V} * \mathrm{~N} / \mathrm{W}$

Where A represents absorbance

$\mathrm{V}$ represents the volume of the solution

$\mathrm{N}$ represents dilution times

W represents the weight of the samples (ug)

\section{B. Influence of ratio of liquid to solid on the extraction rate}

The previous results showed that the greater the ratio of liquid to solid, the smaller the solution concentration, so is the mass transfer driving force and extraction speed. However, the amount of solvent would increase as the ratio of liquid to solid increases and increase the cost of condense afterward. Besides, the higher ratio of liquid to solid could also come up with more impurities in solution. Therefore, it is necessary to select 
and determine the appropriate ratio of liquid to solid. Here the relationship between extraction rate and ratio of liquid to solid was shown in Figure 2.

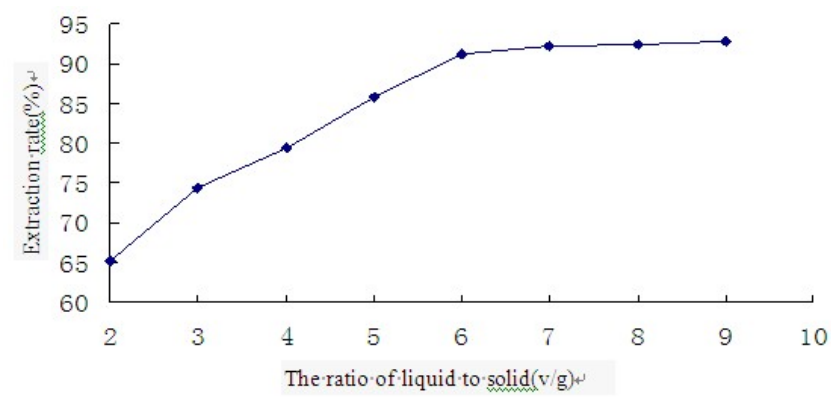

Fig-2 The relation between ratio of liquid to solid and extraction rate

The results showed that extraction rate increased with ratio of liquid to solid substantially, until the extraction rate reached $91.27 \%$ when the ratio comes to $6: 1$. Then increase trend slowed down and maintained in a stable level. Considering the costs of energy consumption and the risk of increasing impurity, 6:1 could be the optimum ratio for the tea saponin extraction.

\section{Influence of temperature on the extraction rate}

As shown in figure 3, extraction rate of tea saponin increased to $90.54 \%$ when the temperature rises from $40^{\circ} \mathrm{C}$ to $80^{\circ} \mathrm{C}$. However, the extraction rate began to decline when the temperature is higher than $80^{\circ} \mathrm{C}$, this is probably the accelerated decomposition rate when the temperature is higher than $80^{\circ} \mathrm{C}$.

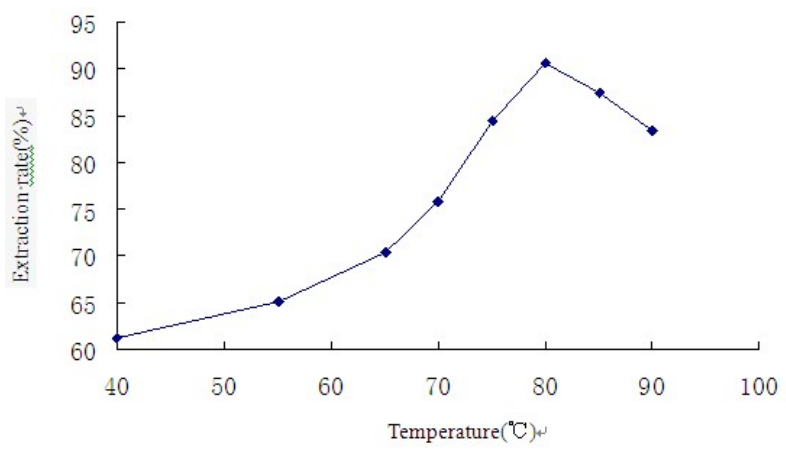

Fig-3 The relation between extraction temperature and extraction rate

\section{Influence of extraction time on the extraction rate}

Theoretically, the leaching process of solute diffused from the inside of the oil -tea camellia seed shell particles to the solution requires a certain time, and thus the extraction rate would increase over prolonged extraction rate, until the mutual transform speed reaches the balance point, the extraction rate will also maintain in a stable level. In order to find out the optimum extraction time, several different extraction time tests were conducted. The results showed that the tea saponin extraction rate increased over time and it reached $89.97 \%$ after $4 \mathrm{~h}$ of extraction. This increase trend slowed down over prolonged time, suggesting balance point of the mutual solute transform could reached at $4 \mathrm{~h}$, which could also be the optimum extraction time for saponin from shell of oil -tea camellia seed shell.

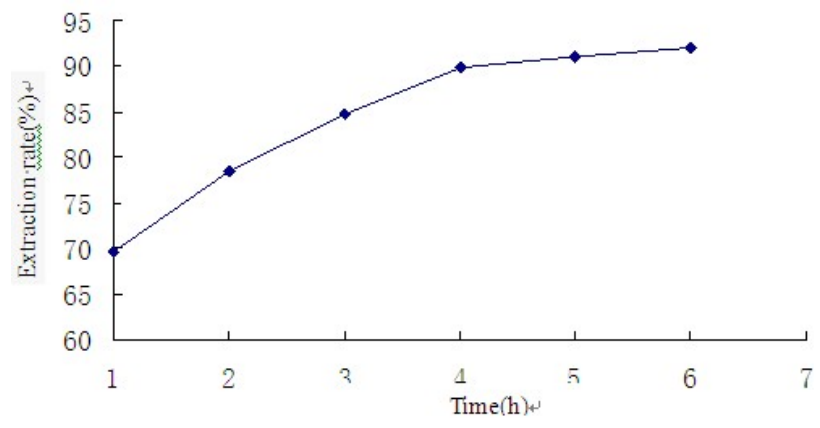

Fig-4The relation between extraction time and extraction rate

\section{E. Influence of $\mathrm{pH}$ on the extraction rate}

As shown in Figure 5, the extraction rate increased with $\mathrm{pH}$ value when the $\mathrm{pH}$ is located between 3 and 10 . The highest extraction rate reached $91.23 \%$ and then the tea saponin extraction rate showed downward trend from $\mathrm{pH} 10$ to 11 . It is notable that tea saponin is a weak acidic substance, and it is conductive for extraction of tea saponin under suitable conditions. However, on the one hand the dissolution of some alkali soluble impurities also excessive, on the other hand some tea saponin decomposition rate would be accelerated under alkaline conditions, which is confirmed from our result that the amount of tea saponin extract declined when the $\mathrm{pH}$ exceeds 10 .

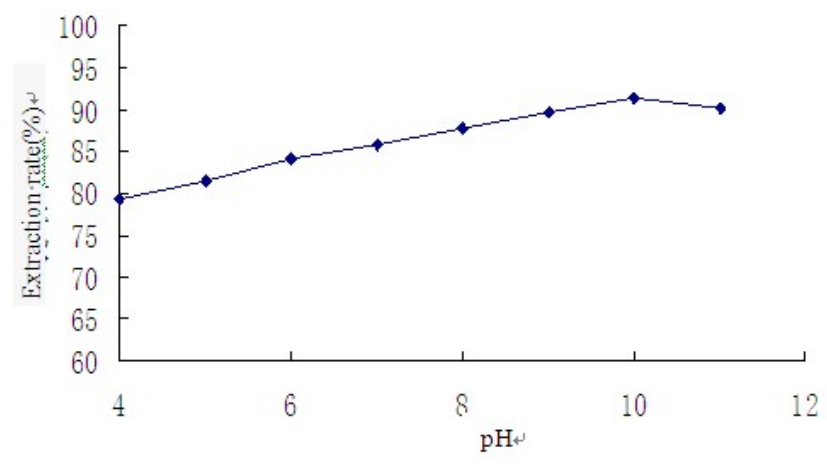

Fig-5 The relation between $\mathrm{pH}$ value and extraction rate

F. Optimization of tea saponin extraction conditions and selection of the optimum level

Orthogonal analysis showed that the main determinants order is $\mathrm{A}>\mathrm{B}>\mathrm{C}>\mathrm{D}$. The extraction temperature showed greatest impact on the tea saponin extraction rate, followed by ratio of liquid to solid and $\mathrm{pH}$ value. While the extraction time showed slightest impact on extraction rate. Therefore, the extraction temperature should be strictly controlled in the optimum level. From the results of orthogonal experiment, the best condition for tea saponin extraction is A2B2C1D3, namely the extraction temperature is $80^{\circ} \mathrm{C}$, ratio of liquid to solid is $6: 1, \mathrm{pH}$ value for extraction is 9 and the extraction time is $6 \mathrm{~h}$. 
TABLE 3. RESULT OF ORTHOGNAL TEST DESIGN AND TEA SAPONINE EXTRACTION RATE

\begin{tabular}{|c|c|c|c|c|c|}
\hline No. & A & B & C & D & extraction rate(\%) \\
\hline 1 & 1 & 1 & 1 & 1 & 91.43 \\
\hline 2 & 1 & 2 & 2 & 2 & 89.79 \\
\hline 3 & 1 & 3 & 3 & 3 & 85.87 \\
\hline 4 & 2 & 1 & 2 & 3 & 92.68 \\
\hline 5 & 2 & 2 & 3 & 1 & 94.66 \\
\hline 6 & 2 & 3 & 1 & 2 & 92.23 \\
\hline 7 & 3 & 1 & 3 & 2 & 86.14 \\
\hline 8 & 3 & 2 & 1 & 3 & 91.74 \\
\hline 9 & 3 & 3 & 2 & 1 & 84.95 \\
\hline $\mathrm{K}_{1}$ & 267.09 & 270.25 & 275.40 & 271.04 & \\
\hline $\mathrm{K}_{2}$ & 279.57 & 276.19 & 267.42 & 268.16 & \\
\hline $\mathrm{K}_{3}$ & 262.83 & 263.05 & 266.67 & 270.29 & \\
\hline $\mathrm{k}_{1}$ & 89.03 & 90.08 & 91.80 & 90.35 & \\
\hline $\mathrm{k}_{2}$ & 93.19 & 92.06 & 89.14 & 89.39 & \\
\hline $\mathrm{k}_{3}$ & 87.61 & 87.68 & 88.89 & 90.10 & \\
\hline $\mathrm{R}$ & 5.58 & 4.38 & 2.91 & 0.96 & \\
\hline
\end{tabular}

\section{G. Determination of the selection and dosage of flocculant}

As shown in Table 4, both poly aluminum chloride and alum could precipitate out the impurities to some extend, but effect of $30 \%$ poly aluminum chloride is better and faster than alum. Furthermore, the size of precipitate particles is also larger with $30 \%$ of poly aluminum chloride than that with alum. The results also showed that $16 \mathrm{~g}$ poly aluminum chloride $(30 \%$ concentration), that is $8 \%$ of the total preliminary extracted liquid, is best option for flocculant as the amount of precipitate produced is low and the saponin rate is also maintained at high level.

TABLE 4 COMPARISON AMONG DIFFERENT FLOCCULANTS

\begin{tabular}{|c|c|c|c|}
\hline Flocculants & $\begin{array}{c}\text { Tea saponin rate } \\
(\%)\end{array}$ & $\begin{array}{c}\text { Precipitate } \\
\text { color }\end{array}$ & $\begin{array}{c}\text { precipitate } \\
\text { amount }\end{array}$ \\
\hline $\begin{array}{c}30 \% \text { poly } \\
\text { aluminum chloride } \\
10 \mathrm{~g}\end{array}$ & 22.74 & brown & a little \\
\hline $\begin{array}{c}30 \% \text { poly } \\
\text { aluminum chloride } \\
16 \mathrm{~g}\end{array}$ & 29.23 & brown & a little \\
\hline $\begin{array}{c}30 \% \text { poly } \\
\text { aluminum chloride } \\
20 \mathrm{~g}\end{array}$ & 31.67 & brown & a lot \\
\hline Alum $1 \%$ & 15.31 & light brown & a little \\
\hline Alum $2 \%$ & 21.78 & light brown & a little \\
\hline Alum 3\% & 25.43 & light brown & a lot \\
\hline
\end{tabular}

\section{H. Determination of CaO amount as precipitate agent}

As shown in Figure 6, saponin precipitation rate showed a higher sedimentation rate as the amount of $\mathrm{CaO}$ increased. However, the precipitate rate decreased as the amount of $\mathrm{CaO}$ exceeded $10 \%$, where the precipitate rate was the highest, reaching $82.86 \%$. This is likely the result of the accelerated saponin decomposition under alkaline conditions induced by the excessive $\mathrm{CaO}$ addition.

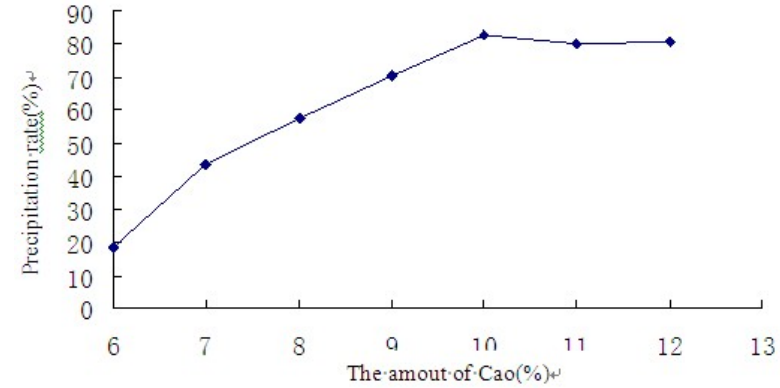

Fig. 6 Effect of $\mathrm{CaO}$ addition on precipitate rate

\section{Determination of ammonium bicarbonate amount as tea saponin release agent}

As shown in Figure 7, the saponin release rate increase with amount of release agent ammonium bicarbonate in the range of $30 \%$ of saponin calcium, in which the saponin release rate reach $72.36 \%$. When the chemical equilibrium reaction rate reached $50 \%$ and the saponin release rate did not improve significantly even if more ammonium bicarbonate was applied.

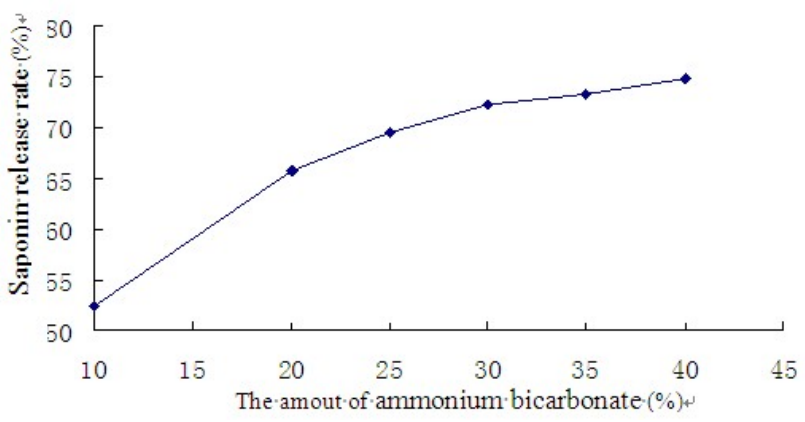

Fig-7 Effect of ammonium bicarbonate on saponin release rate

\section{CONCLUSIONS AND OUTLOOK}

Through this experiment, The most suitable conditions and parameterize the factors were optimized for tea saponin extraction from shell of oil -tea camellia seeds: the extraction temperature is $80^{\circ} \mathrm{C}$, ratio of liquid to solid is $6: 1, \mathrm{pH}$ value for extraction is 9 and the extraction time is $6 \mathrm{~h}$. Poly aluminum chloride $(30 \%$ concentration) is the suitable flocculant and the optimum amount is $8 \%$ of preliminary extracted liquid by weight and placed still for $2 \mathrm{hrs}$. The optimum amount of $\mathrm{CaO}$, as precipitate agent, is $10 \%$ of the weight of the raw materials, and stirred for $4 \mathrm{~h}$. The release agent, ammonium bicarbonate, was used in an amount of the $30 \%$ of the saponin calcium in order to achieve a chemical equilibrium reaction rate of $50 \%$. In this study, we mainly focused on the extraction methods from raw material, not on the saponin purification. Therefore, there are some drawbacks on the process of tea saponin extraction on this aspect, for example, the saponin was also removed with impurities, while some impurities, such as some pigments, tannins, sugars, etc, is still in the solution during the flocculant process. What's more, it is valuable and deserves further investigation asoil -tea camellia seed shell contains many function polysaccharide (e.g. xylose), in addition to tea saponin. Regardsing tea saponin, many difficulties are in the way of tea 
saponin extraction and product development as the cost of industrial production cost is high, purification is very difficult and the content is quite low. In order to meet the industrial production requirements, therefore, more efforts are needs to enforce the researches and studies on the technology of tea saponin extraction and purification process.

\section{REFERENCES}

[1] Qi Xiaojian, Peng Ruifu. Chemistry World[J]. 1989,6: 265-277

[2] Yu Shuying. Hunan Chemical Industry[J]. 1998,28(5): 31-32

[3] Wang Lu, Xia Xiaoping. Evaluating the hydrophilic balance (HLB) values of tea saponin from its chemical structure[J]. Natural Product Research and Development, 1990,2(2): 33-37

[4] Feng Zhiming. Chemicial World[J]. 1994,35(12): 660-662

[5] Lu Xiangyang, Tang Mingyuan. Surface activities of tea saponin and its washing efficiency to silk and wool. Journal of Hunan Agricultural University (Natural Sciences). 2000, 26(3): 218-220

[6] Li Yuntao, Jia Bin. Extracting process of tea saponin and the application in detergent[J]. Journal of Tea Science. 2006,26(3):199-203

[7] Chen Zhibin, Zhang Yuandong.The application of tea saponin on washing of the fine wool fabric[J]. Xinjiang Textile. 1997 (3): 13-14

[8] Xiao Yizhong, Ai Hongrong. The application of tea saponin on the decolorization and detergent[J]. China Surfactant Detergent \& Cosmetics. 1990, 2: 46-48

[9] Zhang Minjie. Sixth conference thesis of comprehensive utilization of agricultural by-products by China committee of Chemistry[J]. 1995, Nanchang

[10] Zhong Haiyan, Xie Bixia, Wang Chengnan. Oil-tea camellia processing and utilization in China[J]. Forest technology exploration. 2001, 15(4): 6-8

[11] Li Qiuting. Promising prospect of healthy oil[J]. Guangxi Forest Research. 2003, 32(3): 154-156

[12] Yuan haiiian, Li Shaohua. The current processing situation and exploration strategies of Camellia oil[Jl. Grain Processing and Food Machinery,2002 (8) :33-34

[13] Peng Yangsheng, Qi Ruchun. Oil-tea camellia cultivation and oil-tea camellia oil extraction[M]. JinDun Press. 2006

[14] Guo Shujin, Xiao yangshu, Fan Yuanjing. Studies on the techniques of processing the oil-tea camellia seed oil[J]. Journal of Anhui Agricultural Sciences, 1996, 24: 285-288

[15] Zhong Kexian. Processing technology of oil-tea camellia seed oil and tea saponin[J]. China Oils and Fats,2002, 27(5): 92-95

[16] Li Xiansheng.Study on the development and utilization of Oil-tea Camellia.Journal of Hunan University of Science and Engineering $[\mathrm{J}]$. 2005,26(11): 127-129 